
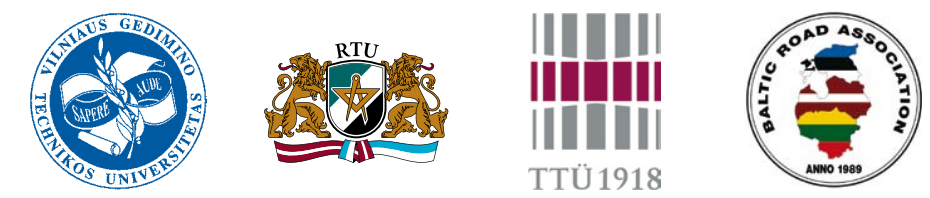

THE BALTIC JOURNAL OF ROAD AND BRIDGE ENGINEERING

\title{
USE OF FWD DEFLECTION BASIN PARAMETERS (SCI, BDI, BCI) FOR PAVEMENT CONDITION ASSESSMENT
}

\author{
Ott Talvik ${ }^{1}$, Andrus Aavik ${ }^{2}$ \\ Dept of Transportation, Tallinn University of Technology, \\ Ehitajate tee 5, 19086 Tallinn, Estonia \\ E-mails: ${ }^{1}$ ott.talvik@ttu.ee; ${ }^{2}$ andrus.aavik@ttu.ee
}

\begin{abstract}
Current research studies relationship between Falling Weight Deflectometer (FWD) deflection basin parameters and road pavement structural condition indicators, such as fatigue cracking and permanent deformations induced by low bearing capacity of pavement, and pavement equivalent $E$ modulus $\left(E_{e q}\right)$. The primary aim of the research was to develop limit values for deflection basin parameters: surface curvature index $(S C I)$, base damage index $(B D I)$ and base curvature index $(B C I)$. Analyses of data derived from the Estonian Road Databank disproved the hypothesis of relationship between deflection basin parameters and pavement defects or rutting. Deflection basin parameters and back-calculated $E_{e q}$ were found to be in good correlation. Strong relationships were found between upper layers indicators (SCI and $B D I)$ and $E_{e q}$. Relationship between subgrade indicator $B C I$ and $E_{e q}$, found in the research, was not very strong. Based on the aforementioned relationships, and the required min equivalent modulus of particular pavement, the equations to determine the limit values of deflection basin parameters for different types of pavements were developed. As the statistical analyses of such extensive database have been done for the first time in Estonia, the determined limit values have to be evaluated in practice and, if needed, corrected.
\end{abstract}

Keywords: FWD, deflection basin, surface curvature index $(S C I)$, base damage index $(B D I)$, base curvature index $(B C I)$, limit value.

\section{Introduction}

Arraigada et al. (2009) have been studied the use of accelerometers to measure pavement deflections due to traffic loads. The finite element models (FEMs) revealed the inability of the accelerometers to measure very slow or quasistatic motion. Chea and Martinez (2008) were carried out three-dimensional finite element (3D FE) simulations of the deflection under a standard axle load in order to detect interface flaws between bituminous and hydraulic layers of composite pavements

Most backcalculation programs used to evaluate the pavement layer properties assume static deflections even though dynamic deflections are generated from the Falling Weight Deflectometers (FWD). Losa et al. (2008) proposed a statistical model for the straight evaluation of critical strains in pavements by using the deflections measured by the FWD and the layer thicknesses without backcalculating layer moduli. The model was calibrated on the basis of experimental data and it is useful to evaluate statistical parameters of the homogeneous sub-sections with the aim to evaluate the residual pavement life taking into account the reliability concepts. A pseudo-static backcalculation procedure Dynamic BALMAT (DYN-BAL) was developed by Seo et al. (2009) to calculate the layer moduli after con- verting dynamic deflections into static deflections. From the test results, it was found that DYN-BAL gives the most reliable results when compared with several other computer codes in use. The results of Bayrak and Ceylan (2008) study demonstrated that the ANN-based models, which were trained to predict the layer moduli by using the FWD deflection basin data and the thickness of the concrete pavement structure, are capable of successfully predicting the rigid pavement layer moduli with high accuracy.

A dynamic analysis based on the spectral element method Grenier et al. (2009) described for the interpretation of FWD tests on flexible pavements. While the deflection basin currently used in static methods gives some details of the pavement response under transient loading, the simulations of FWD tests using the dynamic model suggest that the time histories should be included as well for the interpretation of FWD deflection measurements. In fact, important dynamic phenomena due to inertial effects and viscous effects are only revealed by deflection histories. Grenier and Konrad (2009) presented a robust backcalculation methodology that uses the LevenbergMarquardt iterative minimization technique to identify the value of unknown layer parameters from FWD tests using a dynamic approach based on the spectral element 
method, too. The efficiency of the proposed methodology is demonstrated by interpreting FWD tests on three flexible pavements that cover a variety of structures, soil, and bedrock conditions. Results indicate that the dynamic approach is capable of simulating quite well the measured deflection histories using effective backcalculated moduli. In addition, comparison of critical strains between static and dynamic interpretation of FWD tests indicates that both approaches predict similar traction strains at the bottom of the asphalt concrete layer. However, the prediction of the compression strain in the subgrade with the static approach is erratic compared with the dynamic method. Donovan and Tutumluer (2009) presented a methodology based on analyzing FWD test data between trafficked and non-trafficked lanes to determine the degradation and rutting potential of flexible pavement unbound aggregate layers in comparison to the subgrade damage.

According Dawson et al. (2009) several procedures can be used for the determination of the resilient modulus: laboratory testing, backcalculation with Non-Destructive Testing (NDT) data, and correlations to other soil parameters (California bearing ratio, density, and water content). Backcalculation with NDT data procedure is relatively inexpensive and fast and can be designed to cover representative soils under the pavement network. NDT devices are used to determine pavement structural capacity and for pavement condition assessment. FWD are mostly used NDT devices all over the world because of the testing accuracy, repetitiveness and similarity to the real loading magnitude and duration.

Since using the NDT devices, many different parameters have developed describing their deflection basins. The main purpose of the parameters is to evaluate whole pavement or single layer condition. Widely used FWD deflection basin parameters (DBPs) are presented in Table 1. Different researches (Kim et al. 2000; Park 2001; Tiehallinnon 2006) have shown their utility possibilities as calculating pavement layers modulus of elasticity ( $E$ modulus) or assessing pavement structural condition. Current research focuses on the three basic DBPs (SCI, BDI, BCI) and is trying to find relationship between FWD deflections and pavement condition:

- Surface Curvature Index (SCI) - difference of deflections measured with load cells in the center of the loading plate $\left(d_{0}\right)$ and $300 \mathrm{~mm}$ from the center $\left(d_{300}\right):\left(d_{0}-d_{300}\right)$, which is characterizing condition of the pavement layers;

- Base Damage Index (BDI) - difference of deflections measured with load cells in the distance $300 \mathrm{~mm}\left(d_{300}\right)$ and $600 \mathrm{~mm}\left(d_{600}\right):\left(d_{300}-d_{600}\right)$, which is characterizing condition of the base layers;

Table 1. Widely used FWD deflection basin parameters (Kim et al. 2000; Talvik 2007)

\begin{tabular}{|c|c|c|c|}
\hline Deflection basin parameter & Equation & Unit & Parameter's objective \\
\hline Surface Curvature Index & $\begin{array}{l}S C I=d_{0}-d_{300}, S C I=d_{0}-d_{r} \\
\text { (used also } r \in[450,600] \text { ) }\end{array}$ & $\mu \mathrm{m}, \mathrm{mm}$ & $\begin{array}{l}\text { Characterizing condition of } \\
\text { bound layers }\end{array}$ \\
\hline Base Damage Index & $B D I=d_{300}-d_{600}$ & $\mu \mathrm{m}, \mathrm{mm}$ & $\begin{array}{l}\text { Characterizing condition of base } \\
\text { layers }\end{array}$ \\
\hline Base Curvature Index & $\begin{array}{l}B C I=d_{600}-d_{900}(\text { used in USA }) \\
B C I=d_{900}-d_{1200} \text { (used in Finland) } \\
B C I=d_{1200}-d_{1500} \text { (used in Estonia) }\end{array}$ & $\mu \mathrm{m}, \mathrm{mm}$ & $\begin{array}{l}\text { Characterizing condition of } \\
\text { subbase or subgrade }\end{array}$ \\
\hline Area & $\begin{array}{l}A R E A=\frac{6\left(D_{0}+2 D_{1}+2 D_{2}+D_{3}\right)}{D_{0}} \\
A R E A=\frac{150\left(d_{0}+2 d_{300}+2 d_{600}+d_{900}\right)}{d_{0}}\end{array}$ & $\mathrm{~mm}$ & $\begin{array}{l}\text { Characterizing shape of the } \\
\text { deflection basin close to the load } \\
\text { by the normalized area on the top } \\
\text { of the deflection basin }\end{array}$ \\
\hline Area under pavement profile & $A U P P=\frac{5 d_{0}+2 d_{300}+2 d_{600}+d_{900}}{d_{0}}$ & $\mathrm{~mm}$ & $\begin{array}{l}\text { Characterizing condition of the } \\
\text { pavement upper layers }\end{array}$ \\
\hline Shape factors & $F_{1}=\frac{\left(d_{0}-d_{600}\right)}{d_{300}}, F_{2}=\frac{\left(d_{300}-d_{900}\right)}{d_{600}}$ & - & $\begin{array}{l}\text { Determination of condition of the } \\
\text { layer at the equivalent depth }\end{array}$ \\
\hline Deflection ratio & $D R=\frac{d_{600}}{d_{0}}$ & - & $\begin{array}{l}\text { Determination of condition of the } \\
\text { layer at the equivalent depth }\end{array}$ \\
\hline
\end{tabular}

Note: $d_{0}, d_{300}, d_{600}, d_{900}, d_{1200}, d_{1500}$ - measured deformations at the distance of $0,300,600,900,1200,1500 \mathrm{~mm}$ from the center of the loading plate; $D_{0}, D_{1}, D_{2}, D_{3}$ - measured deformations at the distance of $0 \mathrm{ft}, 1 \mathrm{ft}(305 \mathrm{~mm}), 2 \mathrm{ft}(610 \mathrm{~mm}), 3 \mathrm{ft}(914 \mathrm{~mm}) \mathrm{from}$ the center of the loading plate. 
- Base Curvature Index $(B C I)$ - difference of deflections measured with load cells in the distance $1200 \mathrm{~mm}\left(d_{1200}\right)$ and $1500 \mathrm{~mm}\left(d_{1500}\right):\left(d_{1200}-\right.$ $\left.d_{1500}\right)$, which is characterizing condition of the subgrade.

\section{Initial database of the research and analysis of data}

The aim of the current research was to study employing of FWD deflection basin parameters for pavement condition assessment in Estonia. As the analysis had to rely on larger data than 26 control FWD measurement points (measured 1999-2006 every year) used in the researches until now, it was decided to construct database based on paved state road network data. The data of defects $(29790100 \mathrm{~m} \mathrm{sec}-$ tions), rut depths (24333 $100 \mathrm{~m}$ sections) and FWD measurements (37936 points) was derived from the Estonian Road Data Bank to the initial database. Additionally, different pavement types and traffic loadings were taken into account.

\subsection{Analyze groups of the research ans analysis of data}

As pavement design depends on forecasted traffic loading in the end of service life, it was purposeful to divide analyze groups according to traffic loadings. It has to be mentioned that most Estonian roads have reached the end of their service life, but the traffic loading for the current analysis was determined according to the actual traffic volumes based on the counting data of 2006. Estonian Standard for Road Design (Metsvahi et al. 2005) is determining required min equivalent $E$ modulus $\left(E_{\text {req }}\right)$ and related forecasted traffic loadings and those were used for dividing data into analyze groups (Table 2).

Table 2. Analyze groups, traffic loadings and required $E_{\text {eqmin }}$ (Metsvahi et al. 2005)

\begin{tabular}{ccc}
\hline $\begin{array}{c}\text { Analyze } \\
\text { group }\end{array}$ & $\begin{array}{c}\text { Traffic loading, standard } \\
\text { axle load }(100 \mathrm{kN}), \mathrm{vpd}\end{array}$ & Required $E_{\text {eqmin }}, \mathrm{MPa}$ \\
\hline 1 & $<30$ & 140 \\
2 & $30-59$ & 160 \\
3 & $60-114$ & 180 \\
4 & $115-224$ & 200 \\
5 & $225-439$ & 220 \\
6 & $440-869$ & 240 \\
7 & $>870$ & 260 \\
\hline
\end{tabular}

\subsection{Transformation of measured deflections to the standard load level and standard temperature}

During the standard FWD measurement the dropped weight and dropping height are always the same, but in reality, the load applied to the pavement depends on site conditions. Applied load ( $\left.p_{\text {measured }}\right)$ is affected by the pavement stiffness, its surface profile and the properties of the FWD device.

To have comparable deflection values, they have to be normalized to the standard load by multiplying by the fac- tor $\left(p_{\text {target }} / p_{\text {measured }}\right)$. In our case the target load is $50 \mathrm{kN}$ as standard axle load used in Estonia for pavement design is $100 \mathrm{kN}$. The contact pressure equivalent on a $300 \mathrm{~mm}$ diameter plate for $50 \mathrm{kN}$ load is $707 \mathrm{kPa}$ according COST 336:1999 Falling Weight Deflectometer.

$E$ modulus of the bituminous-bounded layers is dependant on the temperature. Therefore, measured deflections of the same structure at different temperatures are different and depending on the stiffness of the bituminousbounded layers. During the FWD measurements the temperature of the bituminous pavement can vary in the range $+5 \ldots+35^{\circ} \mathrm{C}$. As result of this the measured deflection values have to be corrected to the standard temperature. According to the Estonian guidelines for flexible pavement design Procedure 2001-52, in the case of calculation of the pavement structure to the elastic deformation, standard temperature is $+10^{\circ} \mathrm{C}$. For correction of FWD measured deflection values to the standard temperature $\left(+10{ }^{\circ} \mathrm{C}\right)$ can be used temperature correction factors $\left(K_{t}\right)$, calculated using Eqs in Table 3 (Aavik 2003), depending on the bituminous pavement type and the average temperature of the bituminous layer during the FWD measurement $(T)$.

Table 3. Bituminous pavement layer temperature correction factors $K_{t}$ (Aavik 2003)

\begin{tabular}{cc}
\hline $\begin{array}{c}\text { Pavement layer } \\
\text { type }\end{array}$ & Temperature correction factor $K_{t}$ \\
\hline $\begin{array}{c}\text { Asphalt concrete } \\
\text { Cold bituminous } \\
\text { mix }\end{array}$ & $K_{t}=0.000203 T^{2}-0.014841 T+1.127603$ \\
& $K_{t}=0.000205 T^{2}-0.015198 T+1.135192$ \\
\hline
\end{tabular}

FWD measured deflections are transformed to the standard load level $(50 \mathrm{kN})$ and standard temperature $\left(+10^{\circ} \mathrm{C}\right)$ using following Eq:

$$
d_{r 50 k N T}=d_{r} \times\left(\frac{p_{\text {target }}}{p_{\text {measured }}}\right) \times K_{t},
$$

where: $d_{r 50 k N T}-$ deformation at the load $50 \mathrm{kN}$ and temperature $+10^{\circ} \mathrm{C}$ at the distance $r(\mathrm{~mm})$ from the center of the loading plate, $\mu \mathrm{m} ; d_{r}-\mathrm{FWD}$ measured deflection at contact pressure $p_{\text {measured }}(\mathrm{kPa})$ at the distance $r(\mathrm{~mm})$ from the center of the loading plate, $\mu \mathrm{m} ; p_{\text {target }}-$ contact pressure, corresponding to the $50 \mathrm{kN}$ load $\left(p_{\text {target }}=707 \mathrm{kPa}\right)$; $K_{t}$ - temperature correction factor (Table 3 ).

\subsection{Relationship between Deflection Basin Parameters (DBPs) and pavement defects}

In the current research only longitudinal cracking and alligator cracking (fatigue cracking) were examined. Those types of defects are forming if whole pavement or single layers have insufficient structural capacity and therefore bituminous layers submit fatiguing easier.

As data of these surface deflections has gathered separately, the Partial Defect Sum (PDS) parameter was taken into use to give better comparison. PDS is describing extent of cracks in \% of road surface area on the section of 
$100 \mathrm{~m}$ (Eq 2). The Eq 2 is found on the basis of Defect Sum Eq (used in Estonian Pavement Management System), where are presented all types of defects with their weight coefficients.

$$
P D S=\frac{(0.5 \times L C R A C K+1.0 \times A L L I G) \times 100}{R W I D T H \times 100}, \%,
$$

where: $L C R A C K$ - length of longitudinal cracks, m; $A L L I G$ - extent of alligator cracking, $\mathrm{m}^{2} ; R W I D T H$ - width of road, $\mathrm{m}$.

Analysis of data showed that there is no definite relationship between DBPs and investigated road surface defects. It was clearly stated that presenting any of DBPs and PDS on the graph, the dispersion of data is extensive. Values of determination coefficients $\left(R^{2}\right)$ were less than 0.1 $\left(\mathrm{R}^{2}<0.1\right)$, which is indicating the absences of relationship. For example the SCI vs PDS of dense asphalt concrete surface of analyze Group 2 is presented in the Figure 1.

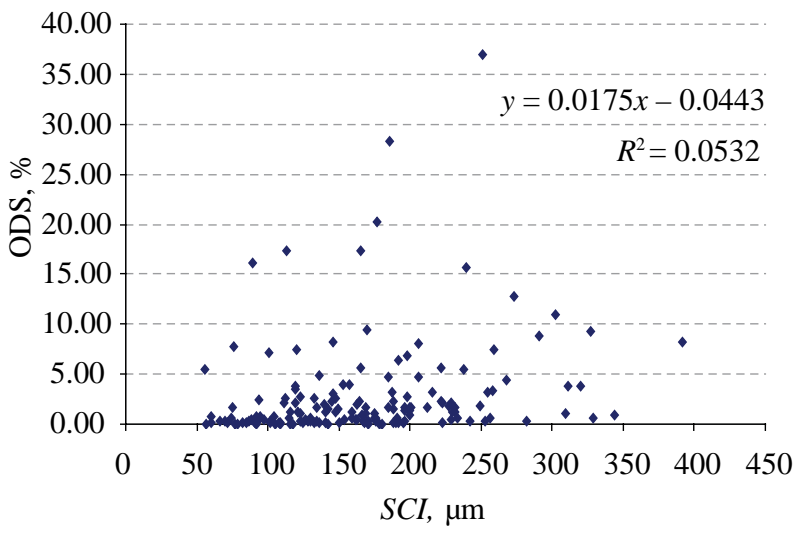

Fig. 1. $S C I$ vs $P D S$ of asphalt concrete surface of analyze group 2

Main reason for absence of the relationship can be the difference between data collection principles: FWD measurements are performed only once per every $100 \mathrm{~m}$ and the measurement represents only the condition of the pavement at this exact point, but other condition indicators are collected from all length of the $100 \mathrm{~m}$ sections. In addition to that the determinations of defects and FWD measurements have been done in different times.

\subsection{Relationship between DBPs and rut depth}

Measurements of rutting in Estonian roads are performed two times a year: in the spring and in the autumn. The depth of rut in the spring is usually smaller than in the autumn, because of different driving trajectory with studded tires in the winter. Reducing the affect of studded tires to the data of rut depths and to survey better permanent deformations, rut depths measured in the autumn were only taken into account.

As the FWD measurements are carried out on the spot of the right wheel lane, the rut depth is taken also from the right wheel lane.

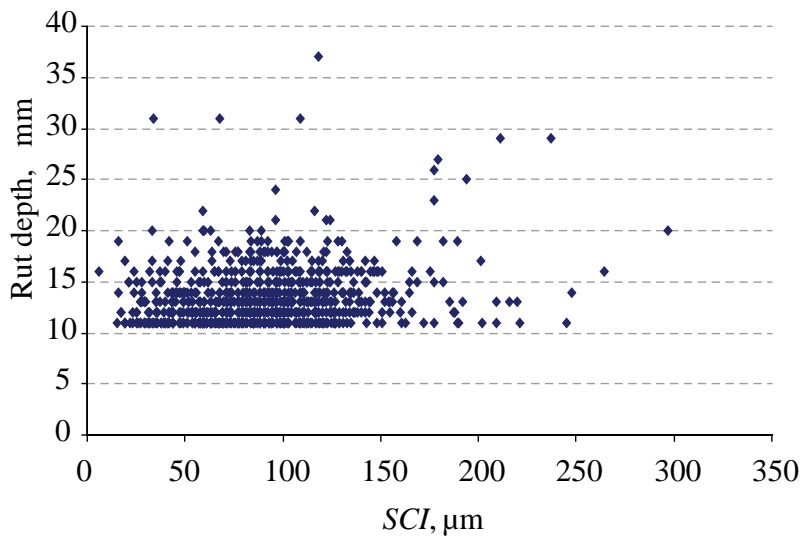

Fig. 2. Values of $S C I$ when rut depth $>10 \mathrm{~mm}$, analyze group 7

It is clearly perceivable in the Fig. 2 that similar rut depths have appeared in the case of different values of SCI. The same situation appeared with other parameters and groups. It is complicated to determine relationships because the rut depths are presented as mean values of the sections, but DBPs represent the pavement condition at the exact point.

\subsection{Relationship between Deflection Basin Parameters (DBPs) and pavement equivalent $E$ modulus $\left(E_{e q}\right)$}

The Eq for back-calculation of pavement equivalent $E$ modulus $\left(E_{e q}\right)$, which is expressed in the $\mathrm{BCH}$ 46-83 "Инструкиия по проектированию дорожных одежд нежесткого типа" [Guidelines for Flexible Pavement Design VSN 46-83] (the previous Soviet Union flexible pavement design procedure), which derivation the Procedure 2001-52 is as follows:

$$
E_{e q}=\frac{0.25 \pi \times\left(1-v^{2}\right) \times F \times S}{d_{0}},
$$

where: $E_{e q}$ - pavement equivalent $E$ modulus at the center of the loading plate, MPa; $v$ - Poisson's ratio (in Procedure 2001-52 v = 0.3); $F$ - contact pressure under the loading plate, $\mathrm{kPa}$; $S$ - diameter of the loading plate, $\mathrm{mm} ; d_{0}-$ deflection at the center of the loading plate, $\mu \mathrm{m}$.

The Eq for the calculation of the $E_{e q}$ comparable with the Procedure 2001-52, taking into account possible different known influencing variables, can be written in the form (Aavik 2003):

$$
E_{e q 2001-52}=C \times E_{e q}^{e} \times T^{t} \times R^{r} \times M_{i} \times H_{j},
$$

where $E_{e q}$ - pavement equivalent $E$ modulus at the center of the loading plate, $\mathrm{MPa}$, calculated using Eq (3); $T$ - mean temperature of the bituminous pavement surface at the moment of FWD measurement, ${ }^{\circ} \mathrm{C} ; R$ - summarized amount of rainfall in 30 days before FWD measurement, $\mathrm{mm} ; M_{i}-$ factor taking into account the month when FWD measurement is performed $(i=4, \ldots, 10$, April-October $) ; H_{j}$ - factor taking into account the height of embankment at the 
FWD measurement site $(j=<0.5 \mathrm{~m} ; 0.5-1.0 \mathrm{~m} ;>1.0 \mathrm{~m})$; $C, e, t, r$-empirical constants.

As during the FWD measurements carried out in the network level the height of the embankment or amount of the rainfall is not known at every measurement site, the Eq (4) can be transformed as follows:

$$
E_{e q 2001-52}=C \times E_{e q}^{e} \times T^{t} \times M_{i},
$$

where $e=0.793 ; t=0.098 ; C=2.039$ (Aavik 2003) and factors taking into account the month $M_{i}$ according to the Table 4.

Table 4. Values of factor $M_{i}$, taking into account the month when measurement is performed (Aavik 2003)

\begin{tabular}{ccccccc}
\hline$M_{4}$ & $M_{5}$ & $M_{6}$ & $M_{7}$ & $M_{8}$ & $M_{9}$ & $M_{10}$ \\
\hline 1.000 & 0.911 & 0.830 & 0.816 & 0.831 & 0.825 & 0.817 \\
\hline
\end{tabular}
Eq (5).

In the analysis onwards used $E_{e q}$ are calculated using

Relationships between DBPs (SCI, BDI, BCI) and back-calculated $E_{e q}(\mathrm{Eq}(5))$ were analyzed. There were examined separately the pavements with and without surface defects, to determine, if there are differences between distressed pavements and undamaged $E_{e q}$ and DBPs. In all analyze groups different pavement types were studied separately.

Getting visual survey from characters relationships, they were presented in the dispersion graphs and regression curves were added. It can to be seen from the Figs 3 and 4 , that most suitable regression line is power function in the form: $y=a_{0} x^{a_{1}}$.

It was found, that relationship between DBPs and $E_{e q 2001-52}$ are quite strong. Relations $S C I-E_{\text {eq2001-52 }}$ and $B D I-E_{\text {eq2001-52 }}$ are described by mathematical functions, which give values of $R^{2}$ between $0.5-0.9$. In the case of relations $B C I-E_{e q}$ values of $R^{2}$ were smaller than 0.5. Also was found, that among the roads, forming the database, appeared to be different values of $B C I$ (characterizing

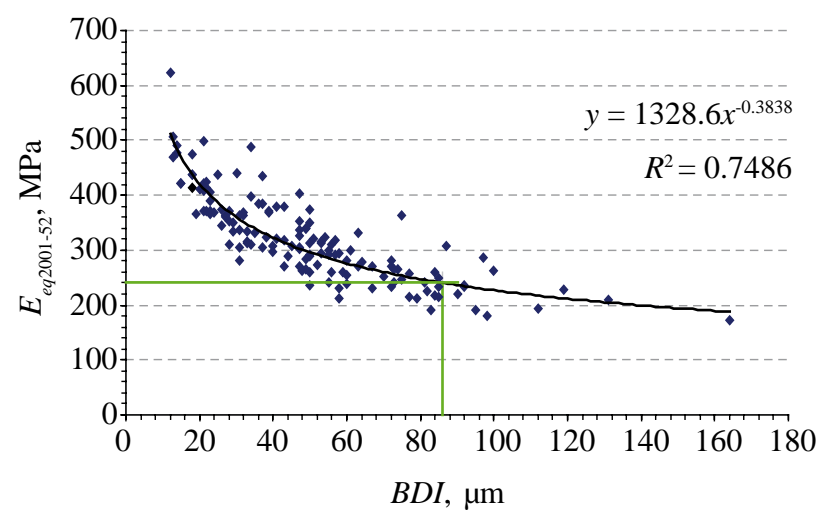

Fig. 3. $E_{\text {eq2001-52 }}-B D I, A C$, analyze group 6, without surface defects

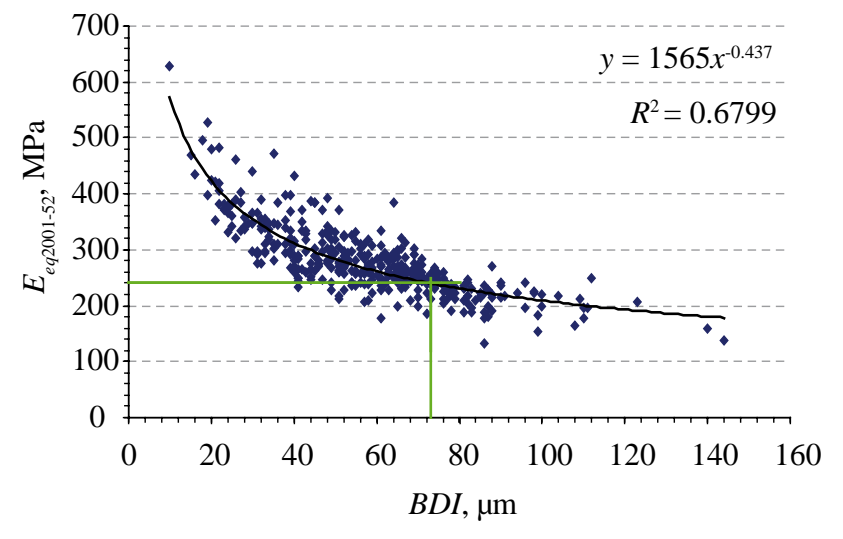

Fig. 4. $E_{\text {eq2001-52 }}-B D I, A C$, analyze group 6, with surface defects

condition of subgrade) in the case of similar E modulus. In the case of different values of SCI and BDI (characterizing upper layers) the divergence of $E_{e q}$ was smaller. This confirms that pavement structural capacity in Estonian roads is assured if there are strong upper layers on the weak subgrades. While the upper layers are also weak, then the whole bearing capacity of the road structure is insufficient. It is illustrated on the Figs 3 and 4, how the value of the DBP was determined according to the min required $E$ modulus $\left(E_{\text {req2001-52 }}\right)$.

During the analyses was found, that there exists no tendency, like pavements with surface defects have bigger values of DBPs. Nevertheless, it was recognized, that values of DBPs are decreasing if the traffic loading (or $E_{\text {req }}$ ) is increasing. This confirms that pavements with higher structural capacity have smaller deflections under the loading.

As usually the $R^{2}$ of mathematical models describing $B C I-E_{e q 2001-52}$ were lower than 0.5 and mostly lower than 0.3 , then pavements that are stabilized with complex binders (bitumen + cement) were found to have higher $R^{2}$ values (0.55-0.88). This shows that subbases with good structural capacity affect strongly on $B C I-E_{\text {eq2001-52 }}$ relationship.

\subsection{Determination of limit values for Deflection Basin Parameters (DBPs)}

On the assumptions of preliminary analysis, based on the $\min E_{\text {req }}$ of particular pavement, the Eqs were developed for calculation the max limit values of deflection basin parameters for different types of pavements. Graphs, where $E_{r e q}$ and DBPs are presented, were composed to as many pavement types as possible. Used mathematical models are power functions, because of the former research which showed non-linearity between parameters and $\mathrm{E}$ modulus:

$$
y=a_{0} x^{a_{1}}
$$

where: $x$ - $\min E_{\text {req }}$ MPa; $y$ - deflection basin parameter (SCI, BDI, BCI); $a_{0}, a_{1}$ - constants according to Table 5 . 
Table 5. Values of constants $a_{0}$ and $a_{1}$ in Eq (6) for calculation of the max allowable deflection basin parameter (SCI, BDI, BCI) values (Talvik 2007)

\begin{tabular}{|c|c|c|c|c|}
\hline \multirow{2}{*}{$\begin{array}{c}\text { Type of pavement } \\
\text { (based on Estonian Road Data Bank) }\end{array}$} & \multirow{2}{*}{$\begin{array}{l}\text { Deflection basin } \\
\text { parameter y }\end{array}$} & \multicolumn{2}{|c|}{ Value of constants } & \multirow{2}{*}{$R^{2}$} \\
\hline & & $a_{0}$ & $a_{1}$ & \\
\hline \multirow{3}{*}{ AC pavement on top of existing pavement } & SCI & 1795660 & -1.70 & 0.83 \\
\hline & $B D I$ & 1265966 & -1.74 & 0.78 \\
\hline & $B C I$ & 51220 & -1.36 & 0.68 \\
\hline \multirow{3}{*}{ AC pavement on top of leveling milling } & SCI & 655780050 & -2.76 & 0.87 \\
\hline & $B D I$ & 15319713999 & -3.47 & 0.93 \\
\hline & $B C I$ & 11182 & -1.13 & 0.09 \\
\hline \multirow{3}{*}{ AC pavement on top of leveling layer } & SCI & 169150407 & -2.54 & 0.92 \\
\hline & $B D I$ & 104111 & -1.27 & 0.38 \\
\hline & $B C I$ & - & - & - \\
\hline \multirow{3}{*}{ AC pavement on bitumen-stabilized base } & SCI & 88410 & -1.113 & 0.54 \\
\hline & $B D I$ & 62337 & -1.161 & 0.51 \\
\hline & $B C I$ & 985977 & -1.909 & 0.35 \\
\hline \multirow{3}{*}{ AC pavement on complex-stabilized base } & SCI & 1225980 & -1.63 & 0.53 \\
\hline & $B D I$ & 137949 & -1.307 & 0.85 \\
\hline & $B C I$ & 49743 & -0.492 & 0.14 \\
\hline \multirow{3}{*}{$\mathrm{AC}$ on crushed stone base } & $S C I$ & 498577 & -1.45 & 0.87 \\
\hline & $B D I$ & 10645 & -0.84 & 0.21 \\
\hline & $B C I$ & 51984 & -1.31 & 0.61 \\
\hline \multirow{3}{*}{ Cold bituminous mix } & SCI & 834463 & -1.55 & 0.97 \\
\hline & $B D I$ & 2055457 & -1.84 & 0.94 \\
\hline & $B C I$ & 983446 & -1.99 & 0.84 \\
\hline \multirow{3}{*}{ Oil shale ash stabilized pavement } & SCI & 2491 & -0.44 & 0.14 \\
\hline & $B D I$ & 1325498 & -1.80 & 0.75 \\
\hline & $B C I$ & 12473680 & -2.43 & 0.44 \\
\hline \multirow{3}{*}{ Surface-dressed gravel pavement } & SCI & 13705 & -0.72 & 0.66 \\
\hline & $B D I$ & 258341445 & -2.83 & 0.96 \\
\hline & $B C I$ & 255760 & -1.87 & 0.95 \\
\hline
\end{tabular}

For example relationship between $S C I-E_{\text {req }}$ of dense asphalt concrete on top of existing pavement (Fig. 5) can be described as follows:

$$
S C I=1795660 E_{\text {req }}^{-1.70}, R^{2}=0.83 .
$$

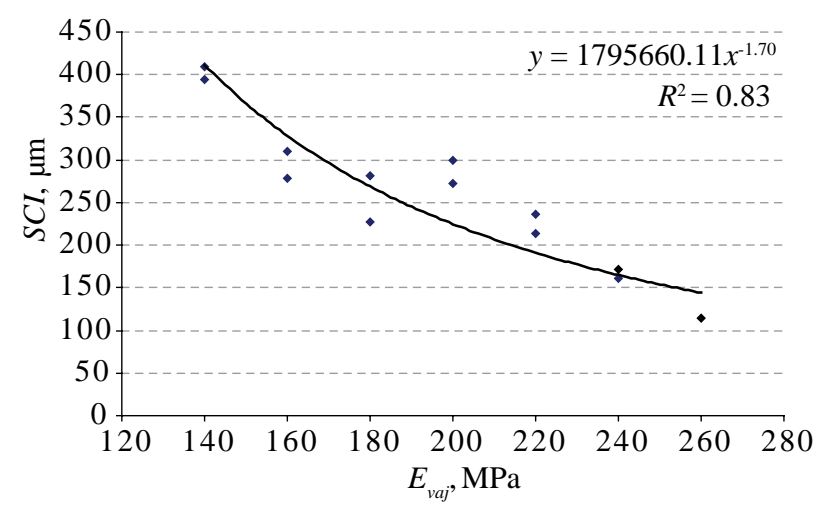

Fig. 5. SCI- $E_{\text {req }}$ AC pavement on top of existing pavement

Based on similar Eqs it is possible to calculate max limit values for min $E_{\text {req }}$ (Table 6).

The Eq for calculation min $E_{\text {req }}$ according Procedure 2001-52 is following:

$$
E_{\text {req }}=(a \log (Q)+b) K_{t b}
$$

where $Q$ - (forecasted) traffic load, standard axle load $\operatorname{vpd}\left(E_{\text {req }} \geq 2\right) ; a, b$ - constants (Table 7); $K_{t t}$ - pavement strength factor (Table 8).
Table 6. DBPs limit values for $E_{\text {req }}$ AC pavement on top of existing pavement

\begin{tabular}{cccc}
\hline$E_{\text {req, }}, \mathrm{MPa}$ & $S C I$ & $B D I$ & $B C I$ \\
\hline 140 & 403 & 233 & 62 \\
160 & 322 & 185 & 51 \\
180 & 263 & 151 & 44 \\
200 & 220 & 125 & 38 \\
220 & 187 & 106 & 33 \\
240 & 161 & 91 & 30 \\
260 & 141 & 80 & 27 \\
\hline
\end{tabular}

Table 7. Values of constants $a$ and $b$ according Procedure 2001-52

\begin{tabular}{cccc} 
& Load group & $a$ & $b$ \\
\hline \multirow{2}{*}{ Lorry } & $\mathrm{A}$ & 67.60 & 61.3 \\
& $\mathrm{~B}$ & 73.37 & -7.7 \\
\multirow{2}{*}{ Bus } & $\mathrm{A}$ & 77.00 & 62.0 \\
& $\mathrm{~B}$ & 84.70 & 0 \\
\hline
\end{tabular}

Table 8. Pavement strength factors according Procedure 2001-52

\begin{tabular}{ccc}
\hline Road class & Pavement & $K_{t t}$ \\
\hline Motorway, I, II & permanent pavement & 1.00 \\
III & permanent pavement & 0.94 \\
III, IV, V & light pavement & 0.90 \\
IV, V & transient pavement & 0.63 \\
V, out of class roads & primitive pavement & 0.63 \\
\hline
\end{tabular}




\section{Conclusions}

Even though it was not succeeded to identify relationships between deflection basin parameters (SCI, BDI, BCI) and pavement surface deflections, the strong relationship with back-calculated $E_{e q}$ proved the practical utility possibilities of DBPs. Stronger relationships were found between upper layers indicators $(S C I$ and $B D I)$ and $E_{e q}\left(E_{e q 2001-52}\right)$, as relationship between subgrade indicator $B C I$ and $E_{\text {eq2001-52, }}$ found in the research, was not very strong.

Analyses confirm that poor condition of Estonian road pavements is due to weak subbases and subgrades. Pavements that are stabilized with mixed binders (bitumen + cement) were found to be with higher $R^{2}$ of mathematical models representing the relationship between $B C I$ and $E_{\text {eq2 } 2001-52}$.

As the statistical analyses of such extensive database have been done for the first time in Estonia, the determined limit values have to be evaluated in practical use and if needed corrected. Initially, deflection basin parameters limit values, developed in this research, can be used for pavement condition assessment in network level. It is possible to determine road sections with insufficient pavement structural capacity using FWD measurements and proposed method for determine max limit values of deflection basin parameters.

\section{References}

Aavik, A.; Paabo, P.; Kaal, T. 2006. Assessment of Pavement Structural Strength by the Falling Weight Deflectometer, The Baltic Journal of Road and Bridge Engineering 1(4): 193-199.

Aavik, A. 2003. Methodical Basis for The Evaluation of Pavement Structural Strength in Estonian Pavement Management System (EPMS). PhD thesis. Tallinn: Tallinn University of Technology. 152 p. ISSN 1406-4766.

Arraigada, M.; Parti, M. N.; Angelone, S. M.; Martinez, F. 2009. Evaluation of Accelerometers to Determine Pavement Deflections under Traffic Loads, Materials and Structures 42(6): 779-790. DOI: 10.1617/s11527-008-9424-4

Bayrak, M. B.; Ceylan, H. 2008. Neural Network-Based Approach for Analysis of Rigid Pavement Systems Using Deflection Data, Transportation Research Record 2068: 61-70. DOI: $10.3141 / 2068-07$

Chea, S.; Martinez, J. 2008. Using Surface Deflection for Detection of Interface Damage Between Pavement Layers, Road Materials and Pavement Design 9(SI): 359-372.

DOI: $10.3166 /$ rmpd.9hs.359-372
Dawson, T. A.; Baladi, G. Y.; Sessions, C. P.; Haider, S. W. 2009. Backcalculated and Laboratory-Measured Resilient Modulus Values, Transportation Research Record 2094: 71-78. DOI: $10.3141 / 2094-08$

Donovan, P.; Tutumluer, E. 2009. Failing Weight Deflectometer Testing to Determine Relative Damage in Asphalt Pavement Unbound Aggregate Layers, Transportation Research Record 2104: 12-23. DOI: $10.3141 / 2104-02$

Grenier, S.; Konrad, J. M. 2009. Dynamic Interpretation of Failing Weight Deflectometer Tests on Flexible Pavements Using the Spectral Element Method: Backcalculation, Canadian Journal of Civil Engineering 36(6): 957-968. DOI: 10.1139/L09-010

Grenier, S.; Konrad, J. M.; LeBaeuf, D. 2009. Dynamic Simulation of Falling Weight Deflectometer Tests on Flexible Pavements Using the Spectral Element Method: Forward Calculations, Canadian Journal of Civil Engineering 36(6): 944-956. DOI: 10.1139/L08-118

Kim, Y. R.; Lee, Y. C.; Ranjithan, S. R. 2000. Flexible Pavement Condition Evaluation Using Deflection Basin Parameters and Dynamic Finite Element Analysis Implemented by Artificial Neural Networks, in ASTM STP 1375 Non-Destructive Testing of Pavements and Backcalculation of Moduli, vol 3. Ed. by Tayabji, S. D.; Lukanen, E. O. American Society for Testing and Materials (ASTM International), West Conshohocken: PA, 514-530. ISBN 0803128584

Losa, M.; Bacci, R.; Leandri, P. 2008. A Statistical Model for Prediction of Critical Strains in Pavements from Deflection Measurements, Road Materials and Pavement Design 9(SI): 373396. DOI: $10.3166 /$ rmpd.9hs.373-396

Metsvahi, T.; Koppel, M.; Pihlak, I. jr. 2005. Maanteede projekteerimisnormid. ptk. 4 - Katendid [Standard for Road Design. Chapter 4 - Pavements]. TTÜ, Teedeinstituut [Tallinn University of Technology, Dept of Transportation].

Park, H. M. 2001. Use of Falling Weight Deflectometer Multi-Load Level Data for Pavement Strength Estimation. PhD thesis. Raleigh, North Carolina.

Seo, J. W.; Kim, S. I.; Choi, J. S.; Park, D. W. 2009. Evaluation of Layer Properties of Flexible Pavement Using a Pseudo-Static Analysis Procedure of Falling Weight Deflectometer, Construction and Building Materials 23(10): 3206-3213. DOI: 10.1016/j.conbuildmat.2009.06.009

Talvik, Ott. 2007. FWD mőőtmistulemuste alusel arvutatud parameetrite SCI, BDI ja BCI kasutamine teekatendi seisukorra hindamisel [Use of FWD Deflection Basin Parameters (SCI, $B D I, B C I$ ) for Pavement Condition Assessment]. Magistritöö [Master thesis]. Tallinn: TTÜ Teedeinstituut [Tallinn University of Technology, Dept of Transportation], $163 \mathrm{p}$.

Received 22 August 2008; accepted 11 November 2009 